\title{
The use of S-guided CREP methodology for advanced seismic structure enhancing processing
}

\author{
Mateusz Zaręba ${ }^{1,2}\left(\mathbb{D} \cdot\right.$ Anna Laskownicka ${ }^{1} \cdot$ Jerzy Zając $^{1}$
}

Received: 23 April 2019 / Accepted: 1 June 2019 / Published online: 11 June 2019

(c) The Author(s) 2019

\begin{abstract}
To acquire refined seismic targets, the use of more accurate and more precise methods of seismic signal processing is crucial. Novel seismic processing approach is even more important in case of the complex geology of mountainous regions (e.g., Carpathians, Carpathian Foredeep) where sub-vertical layering of varying rock complex can be found, but also in case of old seismic data reprocessing (especially when the signal-to-noise ratio and general quality are low). Regardless of many research papers and significant progress in seismic processing techniques, a properly processed and interpreted seismic image is still hardly affordable for this region. Obtaining a new value in seismic data processing is a core function of the presented research. The use of dip-guided filtering combined with beam partitioned analysis and Z-domain dip analysis for reprocessing of 3D and 2D seismic data from the Carpathians region has been studied.
\end{abstract}

Keywords Seismic processing $\cdot$ Image processing $\cdot$ Carpathians $\cdot$ Seismic resolution $\cdot$ Coherency enhancement

\section{Introduction}

The proper seismic imaging of particular layers, related to geological complexes, is being still a big challenge in the case of regions, where complex geology occurs. It is obvious that nowadays, detailed seismic processing requires algorithms and techniques that are created in an innovative way using a combination of well-known seismic procedures and newly adapted techniques from different branches of science and other industries-like image processing (Zareba and Danek 2018a, b; Krasnov et al. 2018; Li et al. 2009), big data analysis (Gupta et al. 2014; Rawat 2014), deep learning neural networks (Lewis and Vigh 2017), and the stock market (Bedi and Toshniwal 2018; Kyoung-jae 2003). There are plenty of established filters for seismic data pre-stack or

Mateusz Zaręba

zareba@agh.edu.pl

Anna Laskownicka

Anna.Laskownicka@gkprocessing.com

Jerzy Zając

Jerzy.Zajac@gkprocessing.com

1 R\&D Department of Seismic Signal Processing Center, GK Processing, Balice, Kraków, Poland

2 The Faculty of Geology, Geophysics and Environmental Protection, AGH UST, Kraków, Poland post-stack filtering, enhancing, and analyzing based on a statistical approach (Wang et al. 2016; Hoeber et al. 2003). While these filters are useful, we noticed that in regions of complicated geology like the Carpathians (please note we will only refer to the Polish Carpathians including Central Carpathians, Outer Carpathians, and Carpathian Foredeep region in general), problematic residual noise occurs when techniques based solely on statistical approach are used, especially when they are directly applied to the parts of the seismic dataset where high-value dips or complicated fault systems are present. The effects of blurring, smearing, and overextending of seismic horizons (when fault systems are under consideration) or flatling the dips or diffractions are unwanted in case of structural interpretation and properly performing time migration algorithms. The main goal of the presented research is to obtain higher vertical and lateral resolutions of final seismic processing products by using objective techniques and tailored algorithms. We propose the combined use of dip-guided filtering (DGF) together with beam partitioned analysis for reprocessing of 3D seismic data from different parts of Carpathians. The presented methodology preserves the real image of the fault system, proper diffractions analysis, and accurate dips reconstruction in the case of high dips and complicated geology. All the above-mentioned components are crucial for proper interpretation and further processing steps (Bashir et al. 2018; 
Zaręba 2016). The use of beam partitioning analysis together with layer- and dip-guided filter in one processing stage has been analyzed because of its advantages in case of improving the signal-to-noise ratio, the proper local magnitude of seismic signal estimation, and relatively easy parallelization (He et al. 2013; Randen and Sonneland 2000). What is important, there are previous successes in application techniques adopted from digital image processing for seismic needs in this region. It has been shown that applying these techniques significantly strengthened useful signal by preventing high-valued dips (in the part where sub-vertical layering can be found), edges, and contact zones of different geological complexes (Zareba and Danek 2018a, b; Zaręba 2016). It is, therefore, reasonable to develop such techniques in order to image subsurface structures even more accurately. We propose the following approach that we named $S$-Guided CREP (Structure-Guided Coherency and Resolution Enhance Processing):

1. Image partitioned analysis of input data.

a. transforming data into Gaussian beams in the decomposition process. It allows for obtaining a fully regularized set of beams that represent locally planar events

b. transforming data back to the time domain in the reconstruction process. It allows for obtaining two different datasets-reconstructed image and the residual image.

The most optimal result is when the noise is stored in the residual dataset and the useful signal is in the reconstructed dataset. This step is being iterated until a satisfying image is obtained;

2. Using data from step 1 , the dip field estimation is performed using $Z$-transform solution—or where the signalto-noise ratio is extremely low, the horizon-guided estimation is done. Please notice that to avoid interpretation of section on the processing stage and to obtain the most objective image, the horizon-guided estimation is performed after performing nonlinear anisotropic diffusion analysis of input structure (Zareba and Danek 2018a, b). In this step, the energy representation of dips field, dips azimuths, structure image, and coherency control file are obtained;

3. The final step is to perform DGF on data obtained from Step 1 guided by the data obtained from Step 2 .

The presented algorithms make it possible to obtain refined seismic targets as well as increase the signalto-noise ratio while preserving information about subvertical layering. The algorithms also help obtain information of deep seismic reflection in the case when the presence of complicated geology of overburden com- plexes caused the poor reconstruction of the seismic signal in the lower parts of seismic sections.

\section{S-guided CREP methodology}

S-Guided CREP consists of three main algorithms: Gaussian beam decomposition and reconstruction of the seismic image, structure-enhanced dip estimation in Z-domain, and dip-guided filtering based on low-pass, Gaussian smoothing filter.

Gaussian beam decomposition and reconstruction (GBDR) is a method commonly used in optical engineering to represent the local wave front (Worku et al. 2018), in seismic surveys for fracture detection for oil and gas recognition of subsurface (Protasov et al. 2015) and for seismic migration (Ross 1990; Tanushev et al. 2011). The process of decomposition is to transform input boundary data into a wavefield using Fourier and Laplace transform (Tanushev 2008; Tanushev et al. 2011). Let consider two-dimensional seismic wave equation using d'Alambert operator:

$\square d \equiv \begin{cases}\partial_{t t} u-c(x) \Delta u=0, & t>0 \\ u=f(x), & t=0 \\ \partial_{t}=g(x), & t=0\end{cases}$

The energy norm can be described in Eq. 2:

$\|u\|_{E}=\frac{1}{2}\left(\int_{R^{d}}\left\lfloor\frac{1}{c(x)}\left|u_{t}\right|^{2}+|\nabla u|^{2}\right\rfloor \mathrm{d} x\right)$

For further needs of Gaussian beam decomposition, solving of the optic geometry form of wave equation is needed:

$u(x, t) \sim a(x, t) e^{i k \phi(x, t)}$

where $\phi(x, t)$ is a phase function and $a(x, t)$ is an amplitude function.

Dip estimation is performed in the Z-domain on the data obtained during beam partitioned analysis using plane-wave destructor filters with linearized inversion (Fomel 2002). On this step, we assume that the obtained image is optimal with a significantly higher signal-to-noise ratio. Let's consider local dip as $\mathrm{d}$ and plan wave equation as:

$w(t, x)=w(t-\mathrm{d} x)$.

Now, the local dip can be suppressed using a partial difference annihilator operator:

$\left(\frac{\partial}{\partial x}+d_{i} \frac{\partial}{\partial x}\right) w(t, x)=0$. 
To find the result of Eq. (5) due to d, the inversion process is needed. It is possible to use the ordinary partial equation to transform data into the frequency domain with the assumption that dip parameter $\mathrm{d}$ is time independent when a small area of interest is under consideration:

$\frac{\partial \widehat{w}}{\partial x}+i \omega d \widehat{w}=0$

where $\widehat{w}$ is simply the Fourier transform of $w$. The general solution of Eq. (6) is assumed as a phase-shift operator:

$\widehat{w}(x)=\widehat{w}(0) e^{-i \omega x d}$

Where complex part of equation 7 represents the shift between traces described by parameter $d$ and parameter $x$ (trace spacing). To obtain the plane wave, the two-term prediction filter is needed in the frequency domain. It is possible to make an assumption that positions of seismic traces refer to $\mathrm{x}$ and it is an integer value. Now to obtain plan-prediction filter, the trace transformation from a particular position to the position of the next trace is needed:

$E_{0} \widehat{w}(x)+E_{1} \widehat{w}(x-1)=0$

where $E_{1}=1$ and $E_{1}=e^{-i \omega d}$. Because of considered waves, the multi-use of the prediction filter is needed to obtain more than one plane wave. In $Z$-domain, it is possible to obtain any prediction-error filter in $F-X$ as follows:

$F\left(Z_{x}\right)=1+E_{1} Z_{x}+E_{2} Z_{x}^{2}+\cdots+E_{N} Z_{x}^{N}$.

The two-term filter that we are using is obtained using Eq. (9), where $Z_{1}, Z_{2}, \ldots, Z_{N}$ are roots of the polynomial (9):

$F\left(Z_{x}\right)=\left(1-\frac{Z_{x}}{Z_{1}}\right)\left(1-\frac{Z_{x}}{Z_{2}}\right) \cdots\left(1-\frac{Z_{x}}{Z_{N}}\right)$.

There is an amplitude gain visible in particular solutions (each of them is a product of the frequency and a slope of a local plane wave) outside unit circle area. To include information about dips and slopes that are varying in time, the equivalent of plan-prediction filter and phase-shift operator in the time domain is needed. The local plane-wave energy is the same during propagation from one trace to another in the frequency domain (spectrum of $e^{i \omega d}=1$ ). To obtain the same effect after transformation to the time domain, the use of an all-pass digital filter is needed:

$\hat{d}_{x+1}\left(Z_{t}\right)=\hat{d}_{x}\left(Z_{t}\right) \frac{B\left(Z_{t}\right)}{B\left(\frac{1}{Z_{t}}\right)}$

where $\hat{d}_{x}\left(Z_{t}\right)$ is the Z-transform of particular trace and allpass filter is given as $\frac{B\left(Z_{t}\right)}{B\left(\frac{1}{Z_{t}}\right)}$. Using Eq. (11) with initial conditions at $\mathrm{x}$, we can obtain a finite-difference solution for solving Eq. (5). Using Eq. (11), there is a possibility to obtain 2-D prediction filter:
$F\left(Z_{t}, Z_{x}\right)=1-Z_{x} \frac{B\left(Z_{t}\right)}{B\left(\frac{1}{Z_{t}}\right)}$

The convolution operator of the seismic data with filter (12) is given as Con $(d)$. Assuming that the local dip parameter d is known and $S$ is addressed to known data, the following target can be defined:

$\operatorname{Con}(d) \boldsymbol{S} \approx 0$

Now, the Gauss-Newton iteration method can solve the linear system:

$\operatorname{Con}^{\prime}\left(d_{0}\right) \Delta d \boldsymbol{S}+\operatorname{Con}\left(d_{0}\right) S \approx 0$

Now the algorithm is as follows:

1. $d_{0}$ is the initial value of dip

2. Obtaining Con' $(d)$ value by differentiating $\operatorname{Con}(d)$ with respect to $d$

3. Dip value is being incremented by value $\Delta d$

4. The initial value $d_{0}$ is updated with $\Delta d$

5. Solve the linear problem again

The above algorithm is the most often used scheme. However, sometimes, when the signal-to-noise ratio is low-e.g., in sub-salt or basalt areas-or where the general data quality and fold are extremely inadequate to the expectations of the interpretation, the hybrid solution of horizon guiding and automatic methods can be used. It is extremely important in such cases to have knowledge about the geology and other geophysical information a priori. It allows for proper horizon corridor placement.

Dip-guided filtering is the last step of S-guided CREP. The input data are final images from GBDR and dip estimation. It allows for high-resolution processing of structures because of detailed dip image and strengthened useful signal after GDBR. For further processing, the low-pass Gaussian filter is used in considered directions separately according to Eq. (14):

$F(d)=\frac{1}{\sqrt{2 \pi \sigma}} \exp \left(-0.5 \frac{d^{2}}{\sigma^{2}}\right)$

where the $F(d)$ is the filter response, the parameter d represents the distance from trace to trace and $\sigma$ is the standard deviation of the distribution (which is equal to the filter width defined by a geophysicist).

Filter from Eq. 14 is applied separately in the inline and crossline direction - optionally the variation can be applied in the time axis as well. The procedure is similar in the case of GDBR. Such filter behavior is extremely important in this stage of processing. We assume that datasets are prepared for time migration or are migrated. In most cases of reflection 
seismic processing, it means that data are after noise attenuation - there should be no multiples, linear or coherent noise (attenuated in Tau- $p, F-K$ domain using advanced signal processing methods like non-uniform coherent noise suppression), and random noise as well. However, sometimes the source of noise is more complicated and disturbances have dual nature which means that they cannot be classified as linear or random noise. They fit-in different proportionsto both these classifications. Furthermore, these phenomena could be azimuthal dependent-in one direction particular disturbance can be more coherent, in other could be more random. We often noticed the presence of such disturbances in the Carpathians and in other data from different parts of the world where the contact zone of overlapping layers and planar sediments is present. Smoothing filters like DFG can handle such noise, which could not be removed in previous processing procedures. However, without structure-guided step, smoothing filter tends to weaken energy reflected from not-planar geological objects and the attenuation increases with slope dip value; it could affect faults system by prolongation of planar horizons and destroy diffraction (if data are un-migrated). It is extremely important to provide a structure and dip field in case of use DGF filter.

\section{Local geology}

The presented study is focused on a different part of Carpathians. In this paper, the division of the Polish, Slovakian and Ukrainian Carpathians after Ślączka (Ślączka et al. 2006) has been used. The cross section between Zakopane and Kraków allows dividing the area into three sections: Central Carpathians, Outer Carpathians, and Carpathian Foredeep (Fig. 1).

The Central Carpathians are separated from the Outer Carpathians by the Pieniny Klippen Belt. We can divide them on Podhale Syncline consisting of Paleogene Flysch (Krobicki and Golonka 2008) dated on Eocene to Oligocene age. This complex is made of shales, sandstones, and mudrocks. The Paleogene parts have different lateral facies parallel to the tectonic strike. The next is not big-sized Zakopane Basin (from Giewont top to the Gubałówka one) which consists mostly of Pleistocene rocks deposited by river and glaciers. The Lipto, Poprad-Hernad, and Nowy Targ Basins are in general made of Paleocene- to Eocene-aged facies of flysch sandstone, shales, and marl rocks. The High Tatras are represented by granitoids, sedimentary complexes (Mesozoic) divide on the autochthonous crystalline core (granitoids) and the shifted complexes from the south in the Late Cretaceous (Foldvary 1988).

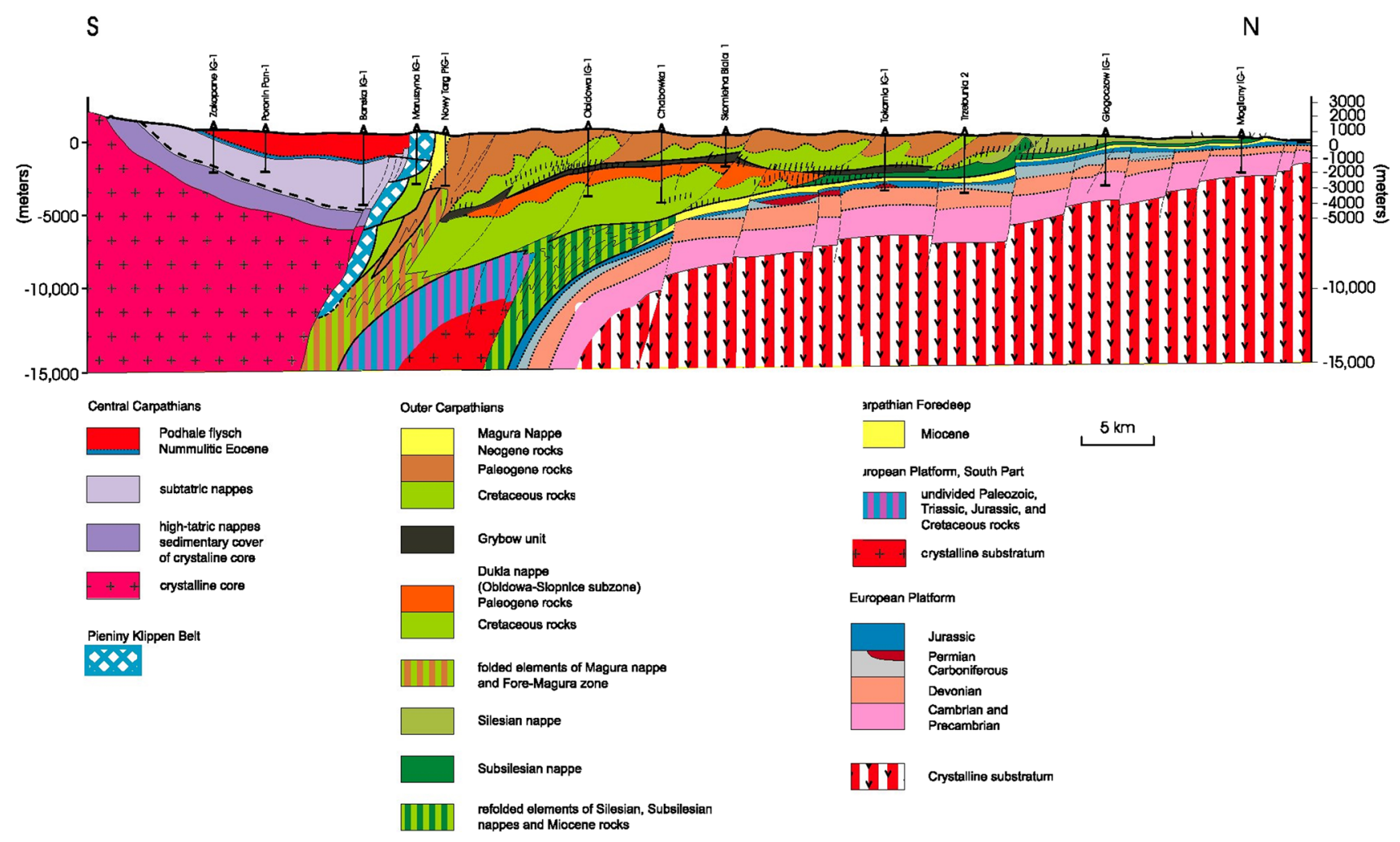

Fig. 1 Generalized cross section through Polish Carpathian (Kraków-Zakopane) (Ślączka et al. 2006) 
The Outer Carpathians consist of varying tectonic system and stratigraphy with different lithologies of thrust sheets and napples. Overthrust of the tectonic units can be seen from the south. Their age is dated from Jurassic to the Miocene (Ślączka et al. 2006; Koszarski and Slaczka 1976; Książkiewicz 1962). Only parts of the central sedimentary basin are not affected by overthrusting movements; other units have been (in general) uprooted. The four main sedimentary basins separated in the Outer Carpathians are (from the north) Skole, Silesian (with Sub-Silesian), Dukla, and Magura. The flysch sediments with the high thickness (locally over $10 \mathrm{~km}$ ) with turbidity currents origin can be found. Sediments vary in both directions-lateral and vertical. This applies to both their thickness and their structure. The three main basin development stages can be described: Jurassic-Albian stage characterized by black shales, Cenomanian Eocene stage with variegated and red shales, and Oligocene-early Miocene stage characterized with bituminous, brown shales (Slaczka et al. 2006).

The Carpathian Foredeep has changing stratigraphy and tectonics in different parts. Typically, the metamorphosed phyllites with meta-argillites are typically for the oldest Neoproterozoic complexes. The tectonic involvement of these complexes was varying; however, the dips over $60^{\circ}$ are present (Moryc and Jachowicz 2000). Ordovician complexes consist of crystal limestone, quartzite, gray-green sandstone (locally with glauconite) (Tomczyk 1963).
Silurian rocks are represented by shales with marl and limestone interbreeds (thickness varying between 20 and $300 \mathrm{~m}$ ) (Jachowicz 2014). Devonian rocks are divided into two different complexes: Lower Devonian represented by gray sandstones, mottled mudrocks, and shales and Upper Devonian represented by dolomite-limestone breccias and carbonate rocks. Triassic rocks form various deposits depending on the period of sedimentation, typically the sandstone of the Lower Triassic, limestone of the Upper Triassic, and mudrock with sandstone of the Kajper (Sienkiewiczówna 1957). In the Upper Jurassic complex, the Bioherms series can be found. They exhibit in the regular lines, mostly on the sea bottom upheaval. Upper Jurassic complex can reach hundreds of meters of a thickness (Gutowski et al. 2007). Sediments of the Lower Cretaceous are analogous to the Upper Jurassic limestone deposits. The difference can be found in strong facial differentiation of the Lower Cretaceous rocks. In Poland, these deposits are present only in the Zagorzyce-Radomyśl-Jatrząbka Stara area (Urbaniec et al. 2007). The autochthonous Miocene deposit with thickness up to over $1000 \mathrm{~m}$ can be found on the substrate surface that was morphologically differentiated. The Quaternary deposits of gravel, clay, and sands have a thickness of no higher than $60 \mathrm{~m}$ (Karnkowski 1994).

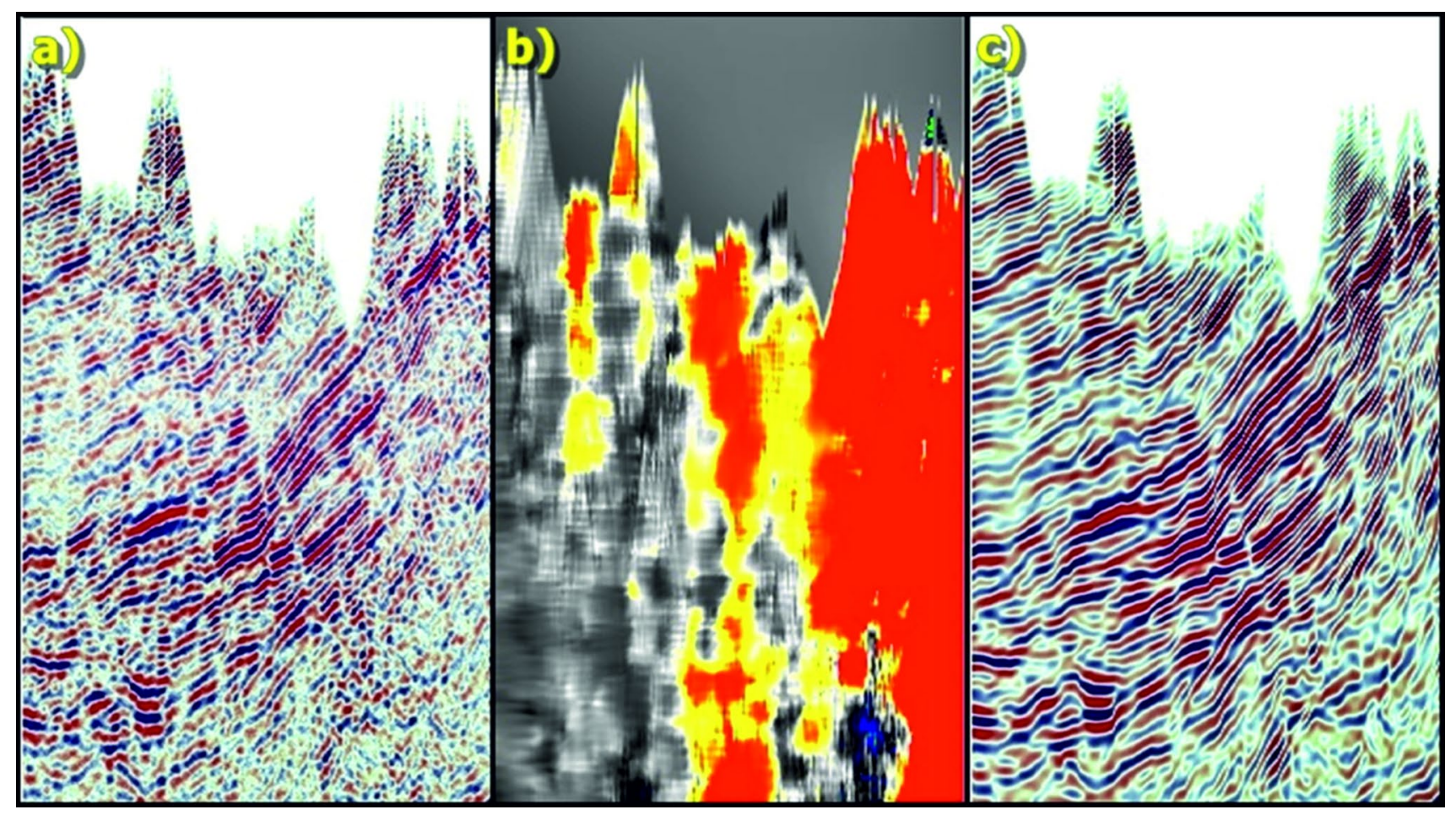

Fig. 2 A comparison of the seismic section of the Carpathian overlap before (a) and after (c) filtering application with dip field estimated in Z-domain (b) 


\section{Application of S-guided CREP for seismic data from the Carpathians region}

Data from the Carpathians region were used in this research. The quality of input data was high with good signal-to-noise ratio. Omega Schlumberger software was used for the processing. The even distribution of sources, receivers and therefore even distribution of offsets and fold allow for maximizing the efficiency of procedures that are used in standard noise attenuation stage $(F-K$, tau- $p$, statistical anomalous amplitude scaling, ground roll removal, etc.), in different gathers-source, receiver, cross-spread or CMP. However, some disturbances were hardly removed, so the nonstandard approach was developed. We used image partitioned analysis based on Gaussian beams decomposition and reconstruction to strengthen the seismic reflection of geological structures for using it in the estimation of dip field. Both of them were then used as an input for DGF procedure based on Gaussian low-pass smoothing filtering approach. Figure 2 illustrates a comparison between the seismic sections after prestack time migration (a), and after PSTM, and S-guided CREP (c). The high-resolution dips field estimated in the $Z$-domain is shown as well (b). The vertical layering of Podhale flysch rocks was not properly restored. As mentioned before, it has been always extremely challenging to obtain the image of sub-vertical and vertical layers of Carpathians flysch rocks. After PSTM, their continuity and strength allowed only for partial interpretation. However, after S-guided CREP application, the useful signal has been significantly strengthened without adding false structures. A similar comparison for Podhale flysch rocks and subtatric and tatric napples is shown in Figs. 3 and 4. It is clearly visible that the seismic signal is strengthened and the signal-to-noise ratio is higher after S-guided CREP application. The particular horizons continuity is much better while fault information is preserved as well. Figures 5 and 6 show deep horizons of crystalline rocks of the Tatra Mountains (two-way travel time (TWT) over $4 \mathrm{~s})$. Before S-guided CREP application, it is hard to

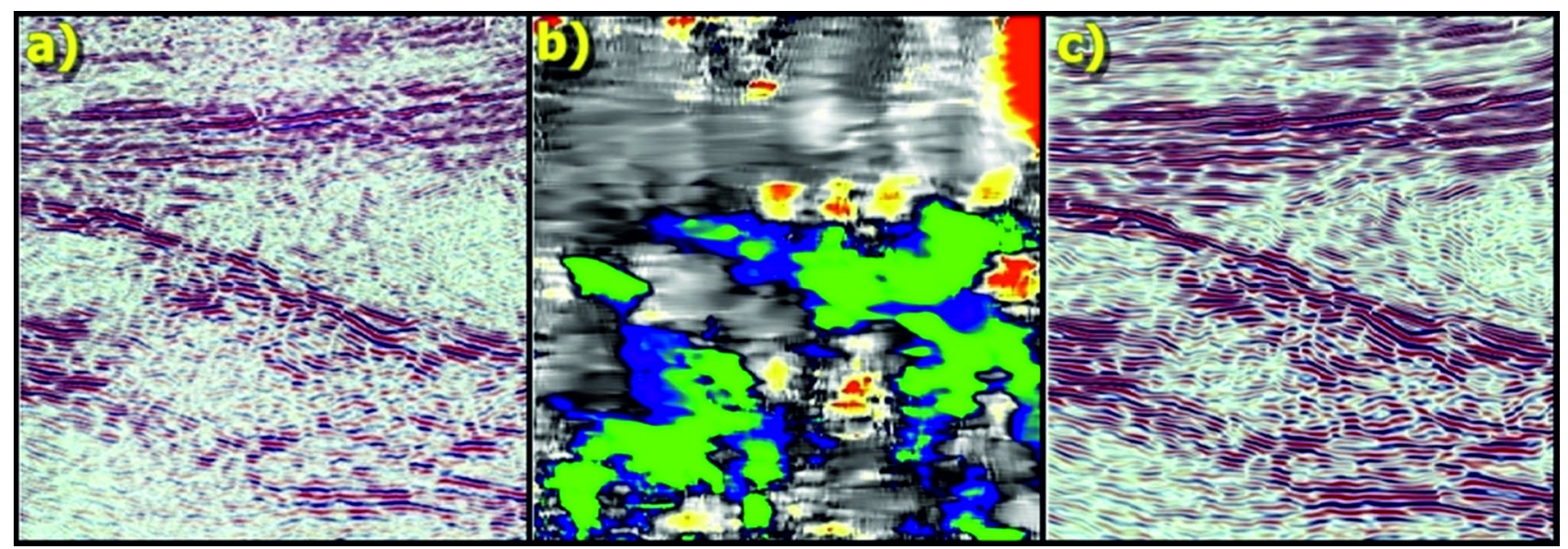

Fig. 3 A comparison of the seismic section of the Podhale flysch rocks before (a) and after (c) filtering application with dip filed estimated in Z-domain (b)

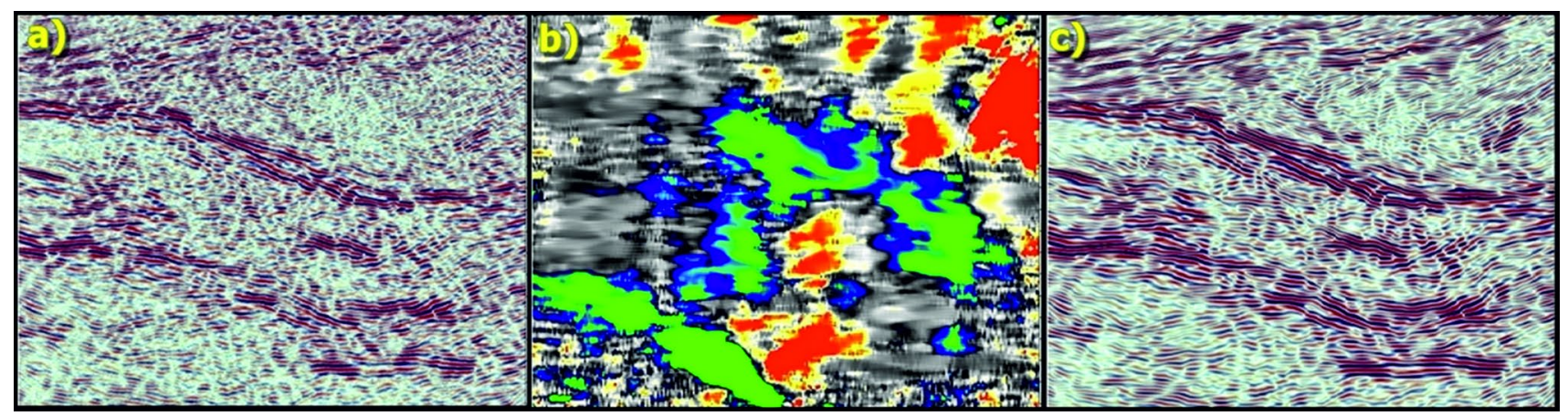

Fig. 4 A comparison of the seismic section of the Podhale flysch rocks and subtatric napples before (a) and after (c) filtering application with dip filed estimated in Z-domain (b) 


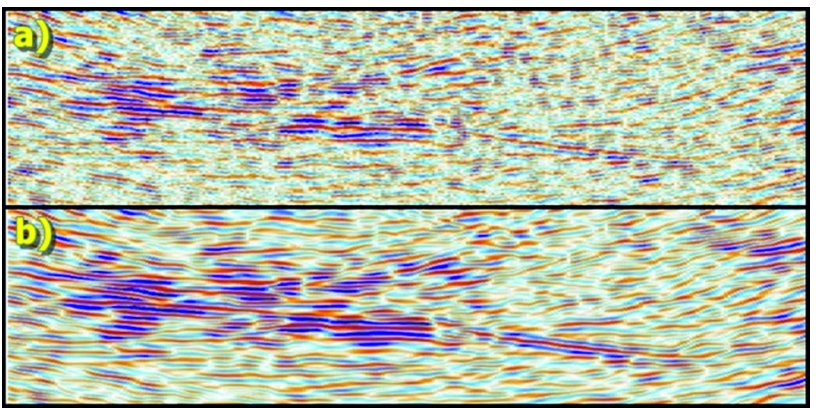

Fig. 5 A comparison of the seismic section of the deep reflection from Tatra's crystalline core rocks (a) and after (b) filtering application

decide whether the signal is the horizon, noise, or migration artifact, but after the presented procedure, it is possible to correlate deep-reflected energy with geological structure and with well logs. Another example of S-guided CREP use can be seen in Fig. 7, where the complete fault system is presented. The seismic image has significantly higher interpretational value than before S-guided CREP. Amplitude spectrum (Fig. 8) before and after filtering is similar. Preserving high frequencies is a strong advantage of S-guided CREP. High dipping layers, fault system, and deep-reflected horizons are preserved, and the reliable interpretation of this region can be easily performed.

\section{Conclusion}

Different types of noise, which can be understood as any part of the recorded seismic signal that is not useful for interpretation, have a different and complex origin. Typical processing procedures based on statistical approach can remove coherent and random noise thanks to the

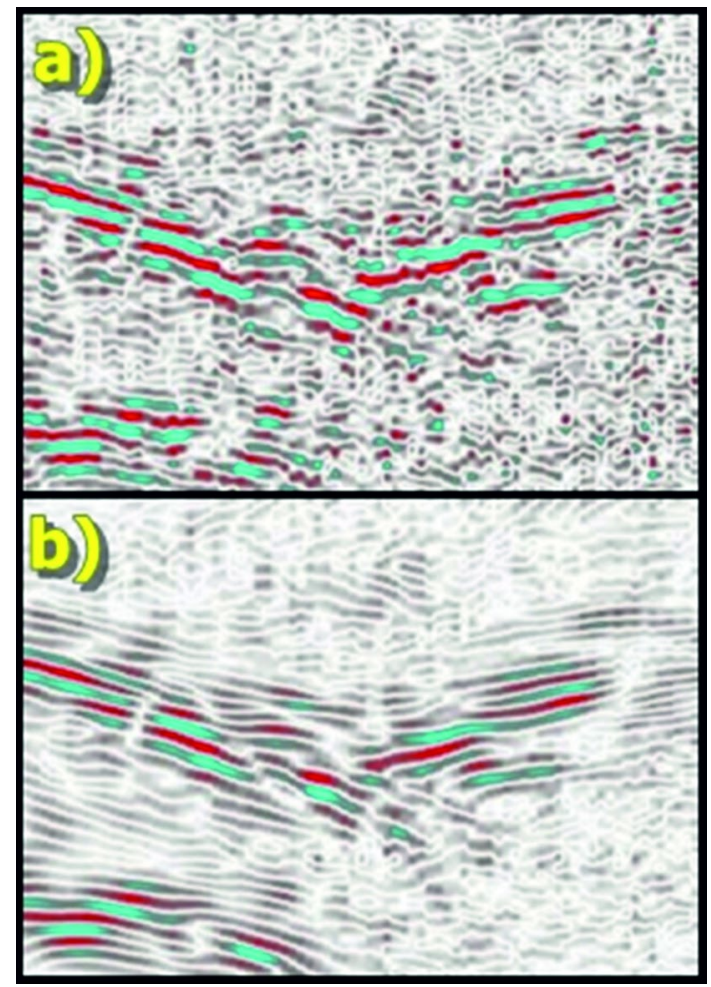

Fig. 7 A comparison of the fault system imaging before (a) and after (b) filtering application

knowledge of their velocity, amplitude, and frequency characteristics. However, there is a specific type of noise whose origin is not covered by the mentioned classification. This type of disturbances is often azimuthal varying in their characteristic. The use of standard procedures in $F-K$, tau- $p$ domain or deconvolution to their removal is sometimes not fully efficient. It results in the background noise which can affect the relative energy changes between particular signal phases and reflection horizons on the
Fig. 6 A comparison of the seismic section of the deep reflection from Tatra's crystalline core rocks (a) and after (b) filtering application

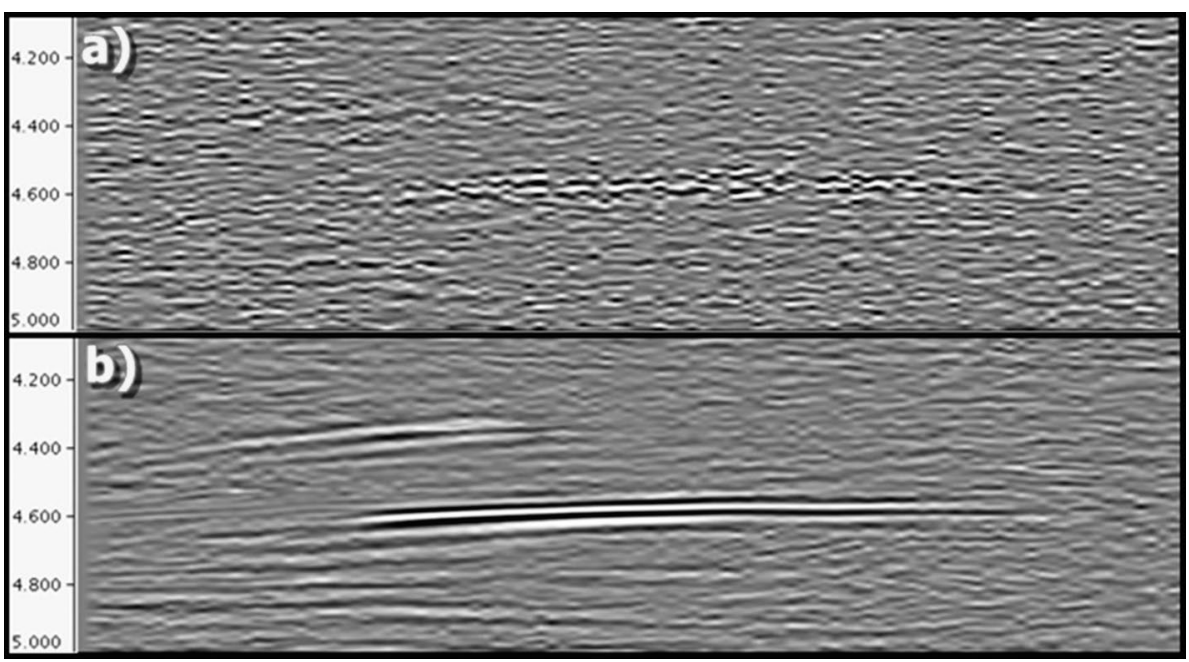


Fig. 8 Amplitude spectrum before (blue) and after (red) S-guided CREP application

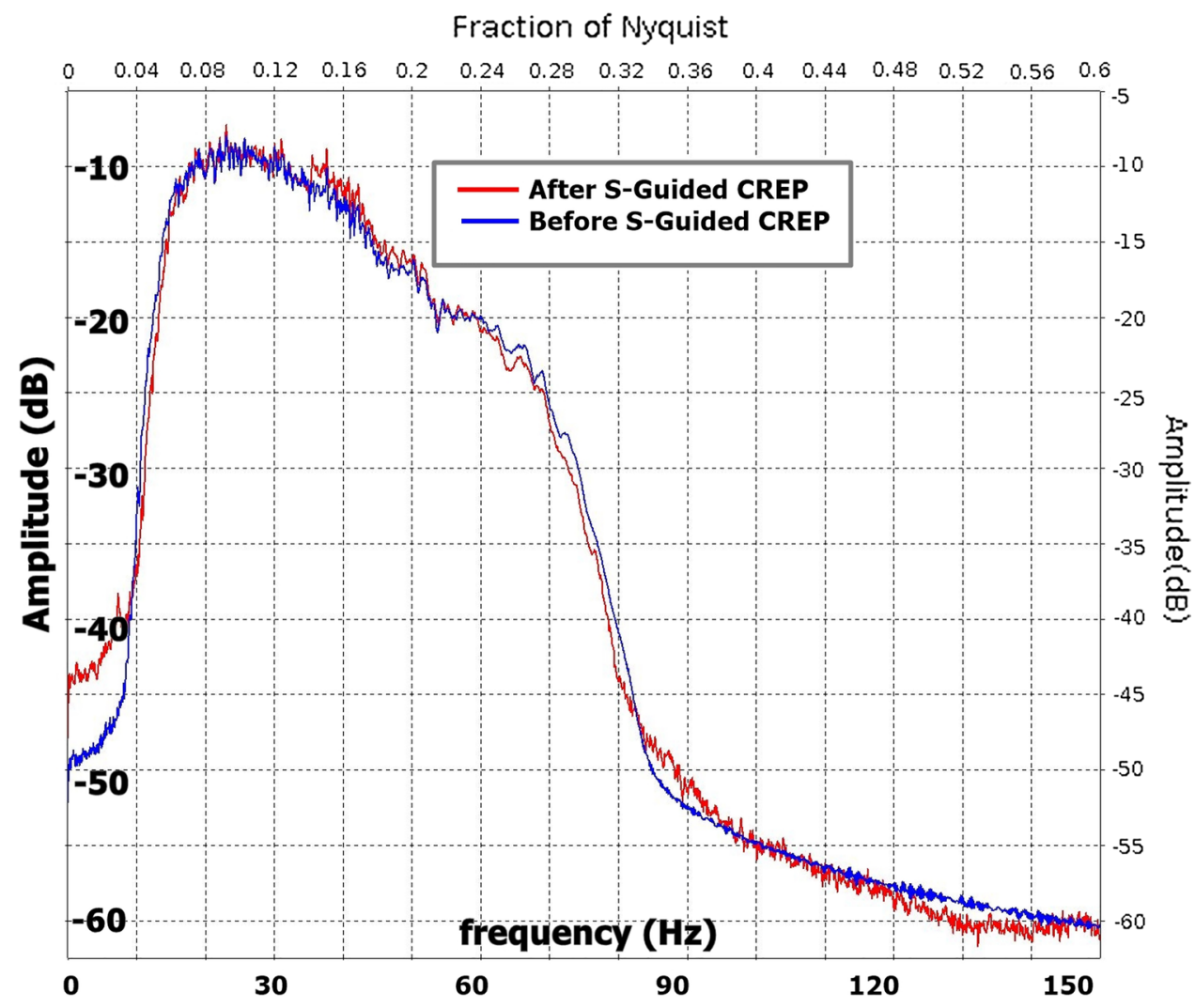

stacked data and in the quasi-linear and quasi-coherent noise which is visible on the stacked data where the contact zone between planar sediments and overlapping, subvertical, high-velocity complexes is present. The use of the presented methodology of S-guided CREP-based on Gaussian image beam partitioned analysis, dip field estimation in Z-domain using plane-wave destructor filter, and Gaussian smoothing filtering-significantly improves the resolution of the final section by overcoming mentioned difficulties that were not removed by other procedures. The presented techniques are associated with well-established digital image processing procedures. This research proved that its use in regions with complicated geology (lito-stratigraphy and tectonics)—-like the Carpathians_-provides the better image of deep-reflected horizons, high-resolution fault system reconstruction, increases the interpretational value of high dipping layers and strengthens the useful signal in the contact zones (between overlapping complexes and planar horizons). Notably, the vertical and horizontal resolution of the seismic signal has been strengthened due to S-guided CREP, with objective structure guiding as a result of the use of $Z$-domain dip estimation and image domain partitioned analysis.

Open Access This article is distributed under the terms of the Creative Commons Attribution 4.0 International License (http://creat ivecommons.org/licenses/by/4.0/), which permits unrestricted use, distribution, and reproduction in any medium, provided you give appropriate credit to the original author(s) and the source, provide a link to the Creative Commons license, and indicate if changes were made.

\section{References}

Bashir Y, Ghosh D, Sum CW (2018) Influence of seismic diffraction for high-resolution imaging: applications in offshore Malaysia. Acta Geophys 66(3):305-316. https://doi.org/10.1007/s1160 0-018-0149-7

Bedi J, Toshniwal D (2018) SFA-GTM: seismic facies analysis based on generative topographic map and RBF, arXiv: $1806.00193 \mathrm{v} 1$

Foldvary GZ (1988) Geology of the Carpathian region. World Scientific Publishing, Singapore, pp 130-157

Fomel S (2002) Applications of plane-wave destruction filters. Geophysics 67:1946-1960. https://doi.org/10.1190/1.1527095

Gupta M, Gupta G, Kumar Sharma M, Singh I (2014) Reflection seismic data analysis using big data. Adv Comput Sci Inf Technol 1(3):103-106

Gutowski J, Urbaniec A, Złonkiewicz Z, Bobrek L, Świetlik B, Gliniak P (2007) Upper Jurassic and lower Cretaceous of the middle polish Carpathian foreland. Biuletyn Państwowego Instytutu Geologicznego 426:1-26

He K, Sun J, Tang X (2013) Guided Image Filtering. IEEE Trans Pattern Anal Mach Intell 35(10):1-13. https://doi.org/10.1109/ TPAMI.2012.213

Hoeber H, Coleou A, Le Meur D (2003) On the use of geostatistical filtering techniques in seismic processing. In: SEG technical program expanded abstracts. https://doi.org/10.1190/1.1817728 
Jachowicz M (2014) The Terreneuvian and late Ediacaran organic microfossils from Kraków area. Biuletyn Państwowego Instytutu Geologicznego 459:61-82

Karnkowski P (1994) 1994), Miocene deposits of the Carpathian Foredeep (according to results of oil and gas prospecting. Geol Q 38(3):377-394

Koszarski L, Slaczka A (1976) The Outer (Flysch) Carpathians: the cretaceous. In: Cieśliński S (ed) Geology of Poland, vol I. Stratigraphy part 2: Instytut Geologiczny, Warszawa, pp 495-748

Krasnov F, Butorin A, Sitnikov A (2018) Automatic detection of channels in seismic images via deep learning neural networks. Bus Inf 2(44):7-16. https://doi.org/10.17323/1998-0663.2018.2.7.16

Krobicki M, Golonka J (2008) Geological history of Pieninny Kippen belt and Middle Jurassic black shales as one of the oldest deposits of the region-stratigraphical position and palaeo enviromental significance. Geoturystyka 2(13):3-18

Książkiewicz M (1962) Geological atlas of Poland: stratigraphic and facial problems. Polish Geol Inst, Wydawnictwa Geologiczne

Kyoung-jae K (2003) Financial time series forecasting using support vector machines. Neurocomputing 55(1):307-319

Lewis W, Vigh D (2017) Deep learning prior models from seismic images for full-waveform inversion. In: SEG technical program expanded abstracts. https://doi.org/10.1190/segam2017-17627 643.1

Li Y, Cheng J, Zhu S, Wang C (2009) Seismic multi-attribute analysis based on RGB color blending technology. J China Coal Soc 11:018-034

Moryc W, Jachowicz M (2000) Precambrian deposits in the BochniaTarnów-Dębica region. Przegląd Geologiczny 48:601-606

Protasov MI, Reshetova G, Tcheverda V (2015) Fracture detection by Gaussian beam imaging of seismic data and image spectrum analysis. Geophys Prospect 64:1. https://doi. org/10.1111/1365-2478.12259

Randen T, Sonneland L (2000) Pre- and post-conditioning. In: Iske A, Randen T (eds) Mathematical methods and modelling in hydrocarbon exploration and production, mathematics in industry, vol 7. Springer, Berlin, pp 42-46

Rawat N (2014) Big data analysis in oil and gas industry. Int J Sci Eng Res 5(5):1-6

Ross HN (1990) Gaussian beam migration. Geophysics 55(11):1416. https://doi.org/10.1190/1.1442788
Sienkiewiczówna H (1957) Geological structure of Miocene substratum in Kraków-Pilzno region. Part 2. The Permian and Mesozoic period. Nafta-Gaz 62(6):263-282

Ślączka A, Kruglow S, Golonka J, Oszczypko N, Popadyuk I (2006) The general geology of the outer Carpathians, Poland, Slovakia, and Ukraine. In: Golonka J, Picha F (eds) The Carpathians and their foreland: geology and hydrocarbon resources Edition: Memoir 84. American Association of Petroleum Geologists, Tulsa, pp 221-258. https://doi.org/10.1306/985610m843070

Tanushev N (2008) Superpositions and higher order Gaussian beams. Commun Math Sci 6(2):449-475

Tanushev N, Richard T, Fomel S, Engquist B (2011) Gaussian beam decomposition for seismic migration. SEG Tech Program Expand Abstr 30(1):3356-3361. https://doi.org/10.1190/1.3627894

Tomczyk H (1963) Ordovician and Silurian in the basement of the Fore-Carpathian depression. Rocz Pol Towarz Geol 33:289-320

Urbaniec J, Urbaniec A, Złonkiewicz Z, Bobrek L, Świetlik B, Gliniak P (2007) Lithostratigraphy and micropalaeontological characteristic of lower Cretaceous strata in the central part of the Carpathian Foreland. Przegląd Geologiczny 58(12):1161-1175

Wang Ch, Wang Y, Xun C (2016) Multicomponent seismic noise attenuation with multivariate order statistic filters. J Appl Geophys 133:70-81. https://doi.org/10.1016/j.jappgeo.2016.07.023

Worku N, Hambach R, Gross H (2018) Decomposition of a field with smooth wavefront into a set of Gaussian beams with nonzero curvatures. J Opt Soc Am A 35(7):1091-1102. https://doi. org/10.1364/JOSAA.35.001091

Zaręba M (2016) Zaawansowane metody zwiększania koherencji sygnału sejsmicznego (The use of advanced seismic techniques to enhance coherency of seismic signal), Cooperation of science and industry in hydrocarbon exploration and production. Conf Mag Oil Gas Inst Kraków 209:201-204

Zaręba M, Danek T (2018a) Nonlinear anisotropic diffusion techniques for seismic signal enhancing-Carpathian Foredeep study. E3S Web Conf 66:01016. https://doi.org/10.1051/e3sconf/2018660101

Zaręba M, Danek T (2018b) VSP polarization angles determination: Wysin-1 processing case study. Acta Geophys 66(5):1047-1062. https://doi.org/10.1007/s11600-018-0200-8 